\title{
Enraizamento de estacas de erva-baleeira em função de diferentes concentrações de ácido indol butírico e número de folhas
}

Rooting of black sage cuttings according to different indole butyric acid concentrations and number of leaves

\section{Adélia Maria Bischoff, Daniel William Vendramim, Erik Nunes Gomes, Katia Christina Zuffellato Ribas, Mara Luana Engel* e Renata de Almeida Maggioni}

Recebido em 11/07/2016 / Aceito em 13/09/2016

\section{RESUMO}

Varronia curassavica Jacq. (Boraginaceae), ervabaleeira, é uma planta medicinal com interesse comercial devido sua atividade anti-inflamatória. A espécie pode ser propagada por sementes, todavia a propagação vegetativa possibilita a obtenção de plantios mais uniformes em relação aos aspectos agronômicos e fitoquímicos. Nesse sentido, objetivou-se com o presente trabalho, avaliar o efeito da aplicação de diferentes concentrações de ácido indol butírico (AIB) e a confecção de estacas caulinares com diferentes números de folhas, na indução da rizogênese da espécie. O experimento foi conduzido no mês de agosto (estação de inverno), em arranjo fatorial $3 \times 2$, com três concentrações de AIB $\left(0,1500\right.$ e $\left.3000 \mathrm{mg} \mathrm{L}^{-1}\right)$ e dois tipos de estacas (estacas confeccionadas com duas folhas ou uma folha). $\mathrm{O}$ experimento foi conduzido em casa de vegetação com nebulização intermitente. Após 60 dias avaliouse a porcentagem de estacas enraizadas, número de raízes por estaca, comprimento das três maiores raízes por estaca, porcentagem de estacas com calos, porcentagem de estacas vivas não enraizadas, porcentagem de estacas mortas e porcentagem de estacas com brotação. Houve diferença significativa para número de raízes por estaca, que foi maior na concentração de $3000 \mathrm{mg} \mathrm{L}^{-1}$ em relação ao tratamento sem aplicação de AIB $(32,5 \%)$, e para porcentagem de estacas com calos $(15,0 \%)$, também maior para estacas com duas folhas na concentração de $3000 \mathrm{mg} \mathrm{L}^{-1}$ de AIB. Para os demais fatores não foi observada diferença estatística entre os tratamentos. Conclui-se que o número de folhas e diferentes concentrações de AIB tiveram baixa influência no enraizamento adventício da espécie, principalmente devido a estação de inverno.
PALAVRAS-CHAVE: Varronia curassavica Jacq., plantas medicinais, propagação vegetativa, auxina.

\section{ABSTRACT}

Varronia curassavica Jacq., black sage, is a medicinal plant with commercial interest due its anti-inflammatory properties. This species can be propagated by seeds, via vegetative propagation enabling the achievement of more uniform crops in relation to the agronomic and phytochemicals aspects. Thus, the present study aimed to evaluate the effect of different concentrations of indole butyric acid (IBA) and different leaf numbers in softwood stem cuttings of black sage plants. The experiment was conducted in august (winter season) in a factorial arrangement $3 \times 2$, with three different concentrations of IBA $\left(0,1500\right.$ and $\left.3000 \mathrm{mg} \mathrm{L}^{-1}\right)$ and two numbers of leaves (two leaves or one leaf). The experiment was conducted in a greenhouse under intermittent mist conditions. At 60 days after planting, the rooting percentage, number of roots per cutting, length of the three longest roots, percentage of cuttings with callus, percentage of live cuttings without roots nor callus, percentage of dead cuttings and percentage of cuttings with shoots were evaluated. There were significant differences for number of roots per cutting, which was higher at a concentration of $3000 \mathrm{mg} \mathrm{L}^{-1}$ compared to treatment without application of IBA $(32.5 \%)$, and for percentage of cuttings with callus $(15.0 \%)$, also higher were cuttings with two leaves at a concentration of $3000 \mathrm{mg} \mathrm{L}^{-1}$ IBA. For other factors there were no statistical differences between treatments. We conclude that the different number of leaves and IBA concentrations had little influence on the adventitious roots, mainly due to the winter season.

Universidade Federal do Paraná, Curitiba, PR, Brasil.

*Autor para correspondência <maraluana_pzo@hotmail.com> 
KEYWORDS: Varronia curassavica Jacq, medicinal plants, vegetative propagation, auxin.

\section{INTRODUÇÃO}

Conhecida popularmente como erva-baleeira, Varronia curassavica Jacq. (Boraginaceae) é uma espécie nativa das Américas, encontrada desde a América Central até o sul do Brasil, sendo característica da restinga litorânea do Ceará até o Rio Grande do Sul. Trata-se de um arbusto ereto, muito ramificado, aromático, de 1,5-2,5 m de altura, amplamente utilizado na medicina caseira (LORENZI \& MATOS 2008).

Suas folhas aromáticas possuem propriedades medicinais com ação anti-inflamatória, antiulcerogênica, antiartrítica, antimicrobiana, antirreumática, analgésica e com propriedades tônicas (CARVALHO JR et al. 2004, LORENZI \& MATOS 2008, MICHIELIN et al.2009). O primeiro fitoterápico produzido no Brasil, o anti-inflamatório de uso tópico Acheflan $^{\circledR}$, foi desenvolvido a partir do óleo essencial de folhas da erva-baleeira, que causou um impacto importante no cenário da indústria farmacêutica brasileira, sendo indicado para o tratamento de tendinite crônica e dores miofasciais (FERNANDES et al. 2007, PASSOS et al. 2007, MEDEIROS et al. 2007, QUEIROZ et al. 2009).

Devido às propriedades terapêuticas da ervabaleeira, existe grande interesse na ampliação de estudos sobre a espécie, principalmente estudos voltados para a seleção de genótipos interessantes quanto aos seus aspectos agronômicos e a sua composição química (VAZ et al. 2006). Visando a produtividade comercial dessa espécie medicinal, são necessários estudos de métodos eficientes para sua propagação.

A propagação natural de Varronia curassavica Jacq. ocorre via semente, porém esse processo de propagação é um processo demorado de multiplicação e também apresenta grande variabilidade com relação à produção de metabólitos, devido a segregação genética, o que torna difícil o plantio comercial uniforme de genótipos com alta capacidade de síntese desses metabólitos. A propagação vegetativa por meio de estacas é a técnica de multiplicação de plantas com maior viabilidade econômica para o estabelecimento de plantio comercial, pois permite a multiplicação de genótipos de interesses e uniformidade de plantio, com menor custo (MENDES et al. 2014).
Algumas espécies apresentam limitações na obtenção de mudas por propagação vegetativa, principalmente devido à dificuldade de enraizamento das estacas em condições naturais. Porém, se essas espécies são classificadas como relativamente fáceis de enraizar, quando submetidas a tratamentos com auxinas sintéticas respondem à emissão radicial (HARTMANN et al. 2011). As auxinas são uma classe de reguladores vegetais envolvidos em muitos aspectos do crescimento e desenvolvimento de plantas. Quando aplicada em órgãos isolados, a auxina, dependendo de sua concentração, pode aumentar a resposta rizogênica (GOULART et al. 2008). O ácido indol butírico tem se revelado como um dos reguladores vegetais mais eficientes na indução de primórdios radiciais visando o enraizamento (CAMARGO \& VIEIRA 2001).

Além do balanço hormonal, o sucesso do enraizamento e da sobrevivência de estacas é influenciado por vários fatores como condição fisiológica da planta matriz, tipo e posição dos propágulos, época de coleta, juvenilidade, presença ou ausência de folhas nas estacas, idade das estacas e fatores ambientais (REZENDE 2007). A presença das folhas na confecção das estacas pode exercer um papel importante e estimulatório para a indução do enraizamento (HARTMANN et al. 2011), pois é nas folhas que ocorre em grande quantidade a produção de hormônios e fotoassimilados necessários à rizogênese (ALVARENGA \& CARVALHO 1983).

Visando melhorar as técnicas de propagação vegetativa de erva-baleeira, o presente trabalho objetivou avaliar o efeito de diferentes concentrações de AIB no enraizamento de estacas caulinares semilenhosas da espécie, confeccionadas com a presença de duas folhas e uma folha.

\section{MATERIAL E MÉTODOS}

O material vegetal utilizado para a confecção das estacas foi coletado no mês de agosto de 2015, no período da manhã, a partir de plantas matrizes de três anos de idade, cultivadas no Setor de Plantas Medicinais e Aromáticas da Estação Experimental do Canguiri, Universidade Federal do Paraná. A Estação possui uma área de 440 ha e está localizada no município de Pinhais, PR. As coordenadas geográficas centrais aproximadas são: latitude $25^{\circ} 23^{\prime} 30^{\prime \prime} \mathrm{S}$ e longitude $49^{\circ} 07^{\prime} 30^{\prime \prime} \mathrm{W}$, com altitude de $930 \mathrm{~m}$.

O tempo entre a coleta e a confecção das estacas foi o mais reduzido possível, visando evitar a 
perda de turgor do material vegetal. As estacas foram confeccionadas no Laboratório de Macropropagação do Departamento de Botânica, Setor de Ciências Biológicas da Universidade Federal do Paraná, Curitiba, PR. Foram confeccionadas estacas caulinares apicais semilenhosas com diâmetro variando entre 0,2 e $0,7 \mathrm{~cm}$, com $10 \mathrm{~cm}$ de comprimento, realizando-se corte em bisel na base e transversal acima da última gema axilar, sendo deixadas duas folhas ou uma folha na porção apical, com sua área reduzida à metade. Após a confecção, foram submetidas a tratamento fitossanitário com hipoclorito de sódio a $0,25 \%$ por 15 minutos, seguido de lavagem em água corrente durante 5 minutos.

Os tratamentos consistiram da aplicação do regulador vegetal AIB em solução 50\% hidroalcoólica, em três concentrações $\left(0,1500\right.$ e $\left.3000 \mathrm{mg} \mathrm{L}^{-1}\right)$ na base das estacas, por um período de 15 segundos, as quais continham uma ou duas folhas cortadas ao meio. $\mathrm{O}$ plantio das estacas foi realizado em tubetes de $53 \mathrm{~cm}^{3}$ contendo vermiculita de granulometria fina como substrato.

O experimento foi conduzido num delineamento inteiramente casualizado em arranjo fatorial $3 \times 2$ (3 concentrações de AIB e dois números de folhas na estaca), com quatro repetições e 20 estacas por unidade experimental, totalizando 80 estacas por tratamento e 480 no total do experimento.

Após 60 dias em casa de vegetação com nebulização intermitente $\left(\mathrm{UR}=90 \%\right.$ e $\left.\mathrm{T}^{\circ} 24 \pm 2{ }^{\circ} \mathrm{C}\right)$, foi realizada a avaliação do experimento. As variáveis analisadas foram porcentagem de enraizamento (estacas com raízes de, no mínimo, $1 \mathrm{~mm}$ de comprimento); número de raízes por estaca (total de raízes emitidas); comprimento das raízes formadas por estaca (comprimento das três maiores raízes formadas, em $\mathrm{cm}$ ); porcentagem de estacas com calos; (estacas vivas com formação de massa celular indiferenciada na base e sem raízes); porcentagem de estacas vivas (estacas vivas que não apresentavam indução radicial nem formação de calos); porcentagem de mortalidade (estacas que se encontravam com tecidos totalmente necrosados) e porcentagem de brotações novas (estacas que apresentaram emissão de novas brotações).

Os dados foram submetidos à análise de homogeneidade de variâncias pelo Teste de Bartlett e, quando homogêneas, as médias foram comparadas pelo Teste de Tukey a 5\% de probabilidade, utilizandose o programa estatístico Assistat 7.4 (SILVA \&
AZEVEDO 2006).

\section{RESULTADOS E DISCUSSÃO}

Para a porcentagem de estacas enraizadas não houve efeito da interação entre as concentrações de AIB e número de folhas. Também não foi observado efeito significativo para os fatores de forma isolada (Tabela 1). Assim, o enraizamento não foi influenciado pela presença de AIB e nem pela quantidade de folhas na estaca. MINDÊLLO NETO (2006) ao avaliar diferentes concentrações de AIB e número de folhas em estacas herbáceas de pessegueiro também não verificou interação entre esses fatores para enraizamento. Em valores numéricos, maiores porcentagens foram observadas em concentrações de $3000 \mathrm{mg} \mathrm{L}^{-1} \mathrm{com}$ duas folhas, onde se obteve até $32,5 \%$ de estacas enraizadas (Tabela 1). Esse aspecto demonstra certa sinergia entre aplicação exógena de auxinas e o fornecimento de reservas pelas folhas para enraizamento nesta espécie.

Os valores encontrados para o enraizamento variaram de 6,25 a $32,5 \%$. O maior valor encontrado, $32,5 \%$, é inferior às porcentagens máximas observadas para a erva-baleeira, no trabalho de MENDES et al. (2014) onde se atingiu 53,3\% com concentração de $2000 \mathrm{mg} \mathrm{L}^{-1}$ de AIB. Um dos motivos que podem justificar essa discrepância é a época do ano em que foram coletadas as estacas, uma vez que a sazonalidade pode interferir no balanço hormonal e metabolismo das plantas, fatores diretamente ligados à capacidade de enraizamento (FACHINELLO et al. 2005).

As estacas utilizadas no presente trabalho foram coletadas durante o inverno. MARANGON \& BIASI (2013) avaliaram enraizamento de três cultivares de mirtilo nas quatro estações do ano, e, para todas, o inverno foi a estação que apresentou os menores índices. LIMA et al. (2011) avaliaram o enraizamento de estacas da espécie medicinal Maytenus muelleri durante as quatro estações do ano e observaram que as coletadas no inverno apresentaram valores médios de enraizamento inferiores $(18,4 \%)$ em relação ao verão $(58,34 \%)$ e outono $(32,03 \%)$, com diferentes concentrações de AIB aplicado em talco, que pode ser explicado, além de outros efeitos morfofisiológicos, pela diferença no balanço hormonal proporcionada pelas condições climáticas. XAVIER et al. (2003), relatam que a baixa temperatura proporciona condições fisiológicas menos favoráveis ao processo de desenvolvimento e crescimento das brotações e, 
Tabela 1 - Porcentagem de enraizamento, número de raízes e comprimento médio de raízes por estaca enraizada de Varronia curassavica, após 60 dias de estaqueamento, em função de diferentes concentrações de AIB $\left(0,1500\right.$ e $\left.3000 \mathrm{mg} \mathrm{L}^{-1}\right)$ e diferente número de folhas (duas e uma folhas).

Table 1 - Rooting percentage, root number and average length of roots per rooted cutting of Varronia curassavica, after 60 days of staking, due to different concentrations of IBA $(0,1500$ and $3000 \mathrm{mg} \mathrm{L}^{-1}$ ) and different number of leaves (two and one sheet).

\begin{tabular}{cccccc}
\hline \multirow{2}{*}{ Variável } & Número de & \multicolumn{3}{c}{ Concentração de AIB $\left(\mathrm{mg} \mathrm{L}^{-1}\right)$} & \\
\cline { 3 - 5 } & folhas & 0 & 1500 & 3000 & Médias \\
\hline \multirow{2}{*}{$\begin{array}{c}\text { Enraizamento (\%) } \\
{ }^{1} \mathrm{CV} \%=86,89\end{array}$} & Duas folhas & 13,75 & 25,00 & 32,50 & $23,75 \mathrm{~A}$ \\
& Uma folha & 6,25 & 12,50 & 17,50 & $12,08 \mathrm{~A}$ \\
\cline { 2 - 5 } & Média & $10,00 \mathrm{a} *$ & $18,75 \mathrm{a}$ & $25,00 \mathrm{a}$ & - \\
\hline \multirow{2}{*}{ Número de raízes } & Duas folhas & 1,58 & 2,09 & 2,81 & $2,16 \mathrm{~A}$ \\
CV\%=64,22 & Uma folha & 1,25 & 1,33 & 3,46 & $2,01 \mathrm{~A}$ \\
\cline { 2 - 5 } & Média & $1,42 \mathrm{~b}$ & $1,71 \mathrm{a} \mathrm{b}$ & $3,13 \mathrm{a}$ & - \\
\hline \multirow{2}{*}{ Comprimento médio } & Duas folhas & 2,81 & 3,66 & 4,70 & $3,72 \mathrm{~A}$ \\
de raízes (cm) & Uma folha & 3,39 & 4,57 & 3,38 & $3,78 \mathrm{~A}$ \\
\cline { 2 - 5 } $\mathrm{CV} \%=62,63$ & Média & $3,10 \mathrm{a}$ & $4,11 \mathrm{a}$ & $4,04 \mathrm{a}$ & - \\
\hline
\end{tabular}

*Médias seguidas pela mesma letra maiúscula na coluna e minúscula na linha não diferem estatisticamente pelo teste de Tukey a 5\% de probabilidade. ${ }^{1} \mathrm{CV} \%$ : coeficiente de variação em porcentagem.

consequentemente, as estacas obtidas apresentam resposta reduzida ao enraizamento. No inverno, a taxa fotossintética é baixa, em consequência da baixa luminosidade e temperatura ambiente. Assim, os metabólitos da fotossíntese são reduzidos, sendo, muitas vezes, insuficientes para a iniciação e desenvolvimento das raízes (ONO \& RODRIGUES 1996). Menores porcentagens de enraizamento obtidas no inverno também foram observadas em outras espécies, como catiguá (Trichilia catigua) (VALMORBIDA et al. 2008), lichieira (Litchi chinensis) (CARVALHO et al. 2005) e mini rosa, Rosa spp. (SARZI \& PIVETTA 2005).

Outro fator importante para o enraizamento de estacas e que pode justificar os baixos valores observados é a porção do ramo da qual foram confeccionadas as estacas. As estacas avaliadas no presente trabalho foram confeccionadas a partir de posições aleatórias nos ramos. LAMEIRA et al. (1997) utilizaram, em experimento com erva-baleeira, apenas estacas oriundas da região apical, e atingiram valores de até $68 \%$ de enraizamento com aplicação de $250 \mathrm{mg} \mathrm{L}^{-1}$ de AIB na base das estacas durante 24 horas. Esses altos valores em relação ao presente trabalho podem ser devido ao fato de que estacas caulinares colhidas de porções apicais dos ramos apresentamse menos lignificadas que as presentes nas porções medianas e basais, podendo refletir na presença de células meristemáticas com metabolismo mais ativo e menor quantidade de compostos fenólicos, o que pode auxiliar no processo de enraizamento (HARTMANN et al. 2011). Além disso, as auxinas endógenas, são sintetizadas nos meristemas apicais, folhas e brotos jovens (TAIZ \& ZEIGER 2013), estando em maiores concentrações em estacas apicais e atuando no enraizamento.

Com relação ao número de raízes por estaca houve diferença significativa apenas para as concentrações de AIB, tendo a concentração de $3000 \mathrm{mg} \mathrm{L}^{-1}$ maior número de raízes $(3,13)$ em relação ao tratamento com $0 \mathrm{mg} \mathrm{L}^{-1}$ (Tabela 1). GONTIJO et al. (2003) relataram também maior número de raízes em estacas de acerola com dois pares de folha com concentrações de AIB de $2800 \mathrm{mg} \mathrm{L}^{-1}$. Este fato é atribuído à maior quantidade de reservas translocadas pelas folhas para promover o desenvolvimento de raízes. De acordo com esses resultados, pode-se sugerir que as mudas produzidas nessas condições podem apresentar um desempenho mais satisfatório em campo devido ao sistema radicial mais desenvolvido, o que contribui para a absorção mais eficiente de nutrientes e consequentemente crescimento da muda (REIS et al. 2000).

Para comprimento médio de raízes, não houve 
diferença entre os tratamentos, apresentando o máximo de $4,7 \mathrm{~cm}$, na concentração de $3000 \mathrm{mg} \mathrm{L}^{-1}$ (Tabela 1). Em estacas de patchouli avaliadas com duas, uma e sem folhas, também não se verificou diferenças para a variável comprimento médio das raízes (GARBUIO et al. 2007). MENDES et al. (2014) ao avaliarem diferentes concentrações de AIB em erva-baleeira, relatam maior comprimento médio de raízes em concentrações de até $3000 \mathrm{mg} \mathrm{L}^{-1}$, fato que atribuem ao estímulo a divisão e alongamento celular promovido pelo regulador vegetal.

O número de estacas vivas não enraizadas e sem a presença de calos não apresentou diferença estatística entre os números de folhas e as concentrações de AIB testadas (Tabela 2). COSTA et al. (2007) também não observaram influência de diferentes concentrações de auxinas aplicadas em estacas de melaleuca, fato corroborado por GARBUIO et al. (2007) os quais relataram não haver diferença estatística entre estacas com uma ou duas folhas para a porcentagem de estacas vivas não enraizadas em patchouli.

Já a porcentagem de calos encontrados foi significativamente maior em estacas com duas folhas na concentração de $3000 \mathrm{mg} \mathrm{L}^{-1}$ (Tabela 2). Segundo HARTMANN et al. (2011), calos são células parenquimatosas resultantes dos novos centros meristemáticos formados próximos aos feixes vasculares junto ao floema. A formação de calos e raízes são processos independentes e sua ocorrência simultânea se explica pelo fato de ambos envolverem o processo de divisão celular e dependerem de condições ambientais favoráveis. Este fato foi observado no presente trabalho quando algumas estacas apresentaram formação de raízes sem a presença de calos e outras apresentaram raízes e calos, bem como algumas apresentaram apenas calos sem a presença de raízes. Segundo BITENCOURT et al. (2010), em espécies de difícil enraizamento, geralmente ocorre a formação de calos antes do enraizamento, daí pode-se inferir que se prolongando a permanência das estacas em casa de vegetação poderia ser uma condição favorável para o aumento de estacas enraizadas de erva-baleeira.

Ressalta-se, todavia, que, mesmo sendo um

Tabela 2 - Porcentagem de estacas vivas, estacas com calos, estacas mortas e estacas com novos brotos, de Varronia curassavica, após 60 dias de estaqueamento, em função de diferentes concentrações de AIB $\left(0,1500\right.$ e $\left.3000 \mathrm{mg} \mathrm{L}^{-1}\right)$ e diferente número de folhas (uma e duas folhas).

Table 2 - Percentage of live cuttings, cuttings with calluses, dead cuttings and cuttings with new shoots of Varronia curassavica, after 60 days of staking, due to different concentrations of IBA $(0,1500$ and $3000 \mathrm{mg} \mathrm{L}^{-1}$ ) and different number of leaves (one and two sheets)

\begin{tabular}{cccccc}
\hline \multirow{2}{*}{ Variável } & Número de folhas & \multicolumn{3}{c}{ Concentração de AIB $\left(\mathrm{mg} \mathrm{L}^{-1}\right)$} & \multirow{2}{*}{ Médias } \\
\cline { 2 - 5 } & & 0 & 1500 & 3000 & \\
\hline \multirow{2}{*}{ Estacas vivas (\%) } & Duas folhas & 41,25 & 36,25 & 26,25 & $34,58 \mathrm{~A}$ \\
${ }^{1} \mathrm{CV} \%=95,83$ & Uma folha & 30,00 & 30,00 & 28,75 & $29,58 \mathrm{~A}$ \\
\cline { 2 - 5 } & Média & $35,62 \mathrm{a} *$ & $33,12 \mathrm{a}$ & $27,5 \mathrm{a}$ & - \\
\hline \multirow{2}{*}{ Estacas com calos (\%) } & Duas folhas & 5,00 & 5,00 & 15,00 & $8,33 \mathrm{~A}$ \\
CV\%=95,83 & Uma folha & 1,25 & 7,50 & 1,25 & $3,33 \mathrm{~B}$ \\
\cline { 2 - 5 } & Média & $3,125 \mathrm{a}$ & $6,25 \mathrm{a}$ & $8,125 \mathrm{a}$ & - \\
\hline \multirow{2}{*}{ Estacas mortas $(\%)$} & Duas folhas & 45,00 & 41,25 & 41,25 & $42,50 \mathrm{~A}$ \\
CV\%=61,31 & Uma folha & 63,75 & 57,50 & 53,75 & $58,33 \mathrm{~A}$ \\
\cline { 2 - 5 } & Média & $54,37 \mathrm{a}$ & $49,37 \mathrm{a}$ & $47,5 \mathrm{a}$ & - \\
\hline Estacas com novos & Duas folhas & 55,00 & 58,75 & 58,75 & $57,50 \mathrm{~A}$ \\
brotos $(\%)$ & Uma folha & 36,25 & 42,50 & 46,25 & $41,67 \mathrm{~A}$ \\
\cline { 2 - 5 } CV\%=62,34 & Média & $45,62 \mathrm{a}$ & $50,62 \mathrm{a}$ & $52,50 \mathrm{a}$ & - \\
\cline { 2 - 5 } & & &
\end{tabular}

*Médias seguidas pela mesma letra maiúscula na coluna e minúscula na linha não diferem estatisticamente pelo teste de Tukey a 5\% de probabilidade. ${ }^{1} \mathrm{CV} \%$ : coeficiente de variação em porcentagem. 
indicativo de condições favoráveis ao enraizamento, as porcentagens de estacas com calos, ainda mais baixas que estacas enraizadas, demonstram que a emissão de raízes em erva-baleeira não depende da formação e diferenciação de calos. Esta baixa porcentagem de calos nas estacas pode ser justificada por uma rota de formação que ocorre diretamente pela diferenciação de células próximas ao sistema vascular e não pela diferenciação de calos (HARTMANN et al. 2011). Inferência semelhante foi relatada no trabalho de STEUPP et al. (2013), que ao avaliarem diferentes concentrações de AIB e porções do ramo em Melaleuca alternifolia, relatam que as baixas porcentagens de estacas com calo evidenciam que a cultura apresenta rizogênese direta.

A porcentagem de estacas mortas também não diferiu entre os tratamentos (Tabela 2), apresentando valores de até $63,75 \%$ em estacas sem aplicação de regulador vegetal com uma folha. Essa alta taxa de mortalidade pode ser devido a diversos fatores como época de coleta não favorável ao enraizamento adventício devido a condições ambientais, balanço hormonal das estacas, entre outros.

Para estacas brotadas não houve diferença significativa na interação entre o número de folhas e concentrações de AIB utilizadas (Tabela 2). É conveniente ressaltar que houve valores relativamente altos (até 58,75\%) de estacas com brotações, o que pode explicar, em parte, os baixos índices de enraizamento observados. DELGADO \& YUYAMA (2010) trabalhando com estaquia de Camu-Camu (Myrciaria dubia) relataram que a espécie apresenta altos índices de enraizamento pelo fato de apresentar a formação de raízes anteriormente à formação de brotos, priorizando a alocação de nutrientes da estaca para o desenvolvimento radicial. Dessa forma a alta porcentagem de estacas brotadas no presente experimento pode indicar que a maior parte das reservas presentes no material foi translocada antes para a formação das brotações para após serem usadas no enraizamento, o que pode explicar, em partes, as baixas porcentagens de enraizamento.

Com base nos resultados obtidos, pode-se atingir a otimização de uma metodologia mais ajustada para a propagação da espécie. Existem diversos outros fatores que exercem um papel importante e estimulatório para a indução do enraizamento de estacas caulinares apicais semilenhosas de ervabaleeira e é por meio de estudos científicos como este que se pode elaborar um protocolo de propagação vegetativa da espécie.

\section{CONCLUSÃO}

Nas condições em que o experimento foi realizado conclui-se que, o número de folhas $\mathrm{e}$ diferentes concentrações de AIB tiveram baixa influência no enraizamento adventício da espécie.

Sugere-se que mais estudos sobre a propagação vegetativa de erva-baleeira sejam desenvolvidos, levando-se em consideração a coleta do material vegetal nas diversas épocas do ano.

\section{REFERÊNCIAS}

ALVARENGA LR \& CARVALHO VD. 1983. Uso de substâncias promotoras de enraizamento de estacas frutíferas. Informe Agropecuário 9: 47-55.

BITENCOURT J et al. 2010. Estaquia de Ginkgo biloba L. utilizando três substratos. Revista Brasileira de Plantas Medicinais 12: 135-140.

CAMARGO PRD \& VIEIRA EL. 2001. Aplicações de reguladores vegetais na agricultura tropical. Guaíba: Livraria e Editora Agropecuária. 132p.

CARVALHO JR PM et al. 2004. Chemical composition and antimicrobial activity of the essential oil of Cordia verbenacea D. C. Journal of Ethnopharmacology 95: 297 301.

CARVALHO CM et al. 2005. Enraizamento de estacas semilenhosas de lichieira utilizando ácido indolbutírico. Revista Brasileira de Fruticultura 27: 95-97.

COSTA AG et al. 2007. Diferentes concentrações de ácido indolbutírico no enraizamento de estacas de melaleuca. Horticultura Brasileira 25: Suplemento.

DELGADO JPM \& YUYAMA K. 2010. Comprimento de estacas de camu-camu com ácido ildol butírico para a formação de mudas. Revista Brasileira de Fruticultura 32: 522-526.

FACHINELLO JC et al. 2005. (Eds). Propagação de Plantas Frutíferas. Brasília: Embrapa Informações Tecnológicas. $221 \mathrm{p}$.

FERNANDES ES et al. 2007. Anti-inflammatory effects of compounds alpha-humulene and (-)-trans-caryophyllene isolated from the essential oil of Cordia verbenacea. European Journal of Pharmacology 569: 228-236.

GARBUIO $\mathrm{C}$ et al. 2007. Propagação por estaquia em patchouli com diferentes números de folhas e tipos de estacas. Scientia Agraria 8: 435-438.

GONTIJO TCA et al. 2003. Enraizamento de diferentes tipos de estacas de aceroleira utilizando ácido indolbutírico. Revista Brasileira de Fruticultura 25: 290-292.

GOULART PB et al. 2008. Efeito dos reguladores de crescimento AIB e ANA no enraizamento de miniestacas de clones de Eucalyptus grandis X Eucalyptus urophylla. 
Revista Árvore 32: 1051-1058.

HARTMANN HT et al. 2011. Plant propagation: principles e practices. 8.ed. Boston: Prentice Hall. 915p.

LAMEIRA OA et al. 1997. Enraizamento de miniestacas de erva-baleeira. Hoticultura Brasileira 15: 114-116.

LIMA DM et al. 2011. Capacidade de enraizamento de estacas de Maytenus muelleri Schwacke com a aplicação de ácido indol butírico relacionada aos aspectos anatômicos. Revista Brasileira de Plantas Medicinais 13: 422-438.

LORENZI H \& MATOS FJA. 2008. Plantas medicinais no Brasil: nativas e exóticas. 2.ed. Nova Odessa: Plantarum. 544p.

MARANGON MA \& BIASI LA. 2013. Estaquia de mirtilo nas estações do ano com ácido indolbutírico e aquecimento do substrato. Pesquisa Agropecuária Brasileira 48: 25-32.

MEDEIROS R et al. 2007. Effect of two active compounds obtained from the essential oil of Cordia verbenacea on the acute inflammatory responses; elicited by LPS in the rat paw. British Journal of Pharmacology 151: 618-627.

MENDES ADR et al. 2014. Reguladores vegetais e substratos no enraizamento de estacas de erva-baleeira (Varronia curassavica Jacq.). Revista Brasileira de Plantas Medicinais 16: 262-270.

MICHIELIN EMZ et al. 2009. Chemical composition and antibacterial activity of Cordia verbenacea extracts obtained by different methods. Bioresource Technology 100: 6615-6623.

MINDÊLLO NETO UR. 2006. Estaquia herbácea de pessegueiro cv. Charme, em função de diferentes concentrações de ácido indolbutírico (AIB) e número de folhas. Revista Brasileira de Agrociência 12: 27-29.

ONO E \& RODRIGUES JD. 1996. Aspectos da fisiologia do enraizamento de estacas caulinares. Jaboticabal: FUNEP. 83p.

PASSOS GF et al. 2007. Antiinflammatory and anti-allergic properties of the essential oil and active compounds from Cordia verbenacea. Journal of Ethnopharmacology 110: 323-333.

QUEIROZ EF et al. 2009. A biodiversidade brasileira como fonte de novas drogas: passado, presente e futuro. Revista de Fitoterapia 9: 31-35.

REIS JMR et al. 2000. Efeito do estiolamento e do ácido indol butírico no enraizamento de estacas do porta-enxerto Pyrus alleryana Dcne. Ciência Agrotécnica 24: 931-938.

REZENDE AA. 2007. Enraizamanto de estacas de candeia (Eremanthus erythrop (DC.) MacLeish). Dissertação (Mestrado em Florestas de Produção). Lavras: UFV. 75f. SARZI I \& PIVETTA KFL. 2005. Efeito das estações do ano e do ácido indolbutírico no enraizamento de estacas de variedades de mini-roseira (Rosa spp.). Científica 33: 62-68.

SILVA FAS \& AZEVEDO CAV. 2006. A new version of the Assistat-Statistical Assistance Software. In: 4 World Congress On Computers In Agriculture. Proceedings... Orlando: ASABE p.393-396.
STEUPP CA et al. 2013. Enraizamento de melaleuca: influência da altura de coleta das estacas e aplicação de IBA. Colloquium Agrariae 9: 1-9.

VALMORBIDA J et al. 2008. Enraizamento de estacas de Trichilia catigua A. Jus (Catiguá) em diferentes estações do ano. Revista Árvore 32: 435-442.

VAZ AAA et al. 2006. Biomassa e composição química de genótipos melhorados de espécies medicinais cultivadas em quatro municípios paulista. Pesquisa Agropecuária Brasileira 41: 869-872.

TAIZ L \& ZEIGER E. 2013. Fisiologia vegetal. 5.ed. Porto Alegre: Artmed. 918p.

XAVIER A et al. 2003. Propagação vegetativa de cedrorosa por miniestaquia. Revista Árvore 27: 139-143. 